\title{
Углеродные пленки, полученные импульсным лазерным методом, и их влияние на свойства GaAs-структур
}

\author{
(C) Ю.А. Данилов ${ }^{1,2}$, М.В. Ведь ${ }^{2}$, О.В. Вихрова ${ }^{2}$, Н.В. Дикарева ${ }^{2}$, М.Н. Дроздов ${ }^{3}$, \\ Б.Н. Звонков ${ }^{2}$, В.А. Ковальский ${ }^{4}$, Р.Н. Крюков ${ }^{2}$, А.В. Кудрин ${ }^{1,2}$, \\ В.П. Лесников ${ }^{2}$, П.А. Юнин ${ }^{3}$, А.М. Андреев ${ }^{1}$ \\ ${ }^{1}$ Нижегородский государственный университет им. Н.И. Лобачевского, \\ 603950 Нижний Новгород, Россия \\ ${ }^{2}$ Научно-исследовательский фризико-технический институт \\ Нижегородского государственного университета им. Н.И. Лобачевского, \\ 603950 Нижний Новгород, Россия \\ ${ }^{3}$ Институт фризики микроструктур Российской академии наук, \\ 603950 Нижний Новгород, Россия \\ ${ }^{4}$ Институт проблем технологии микроэлектроники и особо чистых материалов Российской академии наук, \\ 142432 Московская область, Черноголовка, Россия \\ E-mail: danilov@nifti.unn.ru
}

Поступила в Редакцию 15 апреля 2020 г.

В окончательной редакции 21 апреля 2020 г.

Принята к публикации 15 апреля 2020 г.

Исследованы свойства углеродных слоев, полученных на подложках GaAs методом импульсного лазерного распыления пирографита в вакууме. Оптимальной температурой процесса нанесения является $500^{\circ} \mathrm{C}$; при этом скорость роста углеродных слоев составляла 0.19 нм/с. Спектры комбинационного рассеяния света соответствовали спектру нанокристаллического графита. Углеродные слои имели $p$-тип проводимости, демонстрировали полупроводниковый характер температурной зависимости сопротивления и были использованы в качестве проводящего прозрачного покрытия GaAs-структур с квантовой ямой InGaAs. Структуры обнаруживают значительную электролюминесценцию даже при невысоких токах накачки и фоточувствительность в диапазоне $1.5-2.2$ эВ вплоть до комнатной температуры измерений.

Ключевые слова: углеродные нанослои, графен, электролюминесценция.

DOI: $10.21883 /$ FTP.2020.09.49823.15

\section{1. Введение}

Углеродные наноструктуры, в частности графеновые слои, являются предметом значительного интереса исследователей в связи с замечательными физическими свойствами: высокой теплопроводностью, проводимостью, совместимостью с современной полупроводниковой микроэлектроникой. Углеродные слои находят эффективное применение в технологии различных полупроводниковых приборов оптоэлектроники, например, в качестве прозрачных контактных покрытий солнечных элементов [1].

Известен [2] ряд методов формирования углеродных нанослоев на поверхности твердых тел (для оптоэлектроники в первую очередь интересны поверхности полупроводников и полупроводниковых гетероструктур). „Классический“ метод микромеханического расслоения графита [3] хотя и позволяет получать даже однослойный графен, но латеральный размер графеновых листов невелик, а перенос углеродного слоя на поверхность твердотельной структуры представляет собой сложную проблему. Жидкофазное расслоение графитового порошка при ультразвуковой обработке с последующим центрифугированием позволяет получать суспензии, содержащие листы графена, имеющие определенные распределения по числу слоев [4], зависящие от режимов обработки. Последующее осаждение на поверхность полупроводниковой или диэлектрической подложки, например, методом Ленгмюра-Блоджетт, позволяет создавать [4] покрытия для приборов различного назначения (в частности, тензодатчиков [5]).

Формирование графена на поверхности пластин $\mathrm{SiC}$ в результате высокотемпературной $\left(1500-2000^{\circ} \mathrm{C}\right)$ термообработки является достаточно распространенным приемом [6]. Если же использовать для приборов другие подложки (например, GaAs), то проблема переноса углеродного слоя с поверхности карбида кремния не имеет простого решения, а это значительно усложняет технологию.

Метод осаждения углеродных слоев из паровой фазы (CVD-метод) предполагает термокаталитическое разложение углеводородов на поверхности ряда металлов $(\mathrm{Ni}, \mathrm{Cu})$. Синтез происходит, например, при использовании метана при температурах $\sim 1000^{\circ} \mathrm{C}$ в потоке водорода и аргона [2]. Метод обладает рядом несомненных достоинств: позволяет создавать покрытия на большой площади, процесс осаждения хорошо управляется. Проблемы интегрирования метода в технологию приборов связаны в первую очередь с необходимостью перенесения углеродных пленок с металла на поверхность полупроводника. Кроме того, присущее методу включение в состав углеродных слоев атомов водоро- 
да является нежелательным фактором. В этом смысле вакуумные методы получения углеродных слоев имеют потенциальные преимущества.

Метод импульсного лазерного нанесения (ИЛН) [7] является достаточно гибким приемом, который, например, позволяет в одном технологическом цикле получать слоистые структуры, включающие, кроме углеродных слоев, слои металлов-катализаторов формирования графена (в частности, $\mathrm{Ni}$, Со и др.) в любом порядке (сверху, снизу или с обеих сторон углеродных слоев). Сведений о нанесении углеродных пленок методом ИЛН на поверхность GaAs в литературе нами не обнаружено. Отметим, что формирование пленок графена CVD-методом ранее использовано для изготовления арсенид-галлиевых приборных структур, в частности, для создания солнечных элементов [8], хотя при этом графеновая пленка сначала выращивалась на медной фольге и уже потом переносилась на GaAs.

В настоящей работе приведены результаты исследований влияния параметров процесса импульсного лазерного нанесения на свойства углеродных слоев и характеристики GaAs-приборов с углеродным покрытием.

\section{2. Методика эксперимента}

Для формирования углеродных слоев использован метод импульсного лазерного нанесения в вакууме (давление $<10^{-6}$ Торр). Мишенью служила пластина пирографита, а источником излучения был АИГ: $\mathrm{Nd}$-лазер LQ 529, работающий на второй гармонике (длина волны 532 нм) с длительностью импульса 10 нс, частотой повторения 10 Гц, энергией в импульсе 250 мДж. Излучение лазера было сфокусировано на мишени в

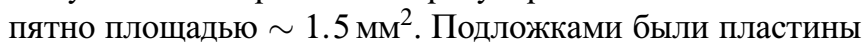
$i$-GaAs $(001)$ или GaAs-структуры с квантовой ямой (КЯ) $\operatorname{In}_{x} \mathrm{Ga}_{1-x}$ As $(x=0.15$, толщина 8-10 нм). Последние были выращены методом МОС-гидридной эпитаксии при $600^{\circ} \mathrm{C}$. Предварительно пластины GaAs обрабатывались кипячением в толуоле и ацетоне с последующей промывкой в деионизованной воде. Непосредственно перед помещением в вакуумную камеру подложка GaAs погружалась для удаления естественного окисла в 20\%-й водный раствор HF на несколько секунд до скатывания. Кроме того, для удаления адсорбатов перед процессом ИЛН подложка прогревалась в вакууме при $400^{\circ} \mathrm{C}$ в течение 25-30 мин. В некоторых случаях для определения характеристик слоев подложкой служил монокристаллический $\mathrm{Si}(100)$, образцы которого проходили аналогичную подготовку.

Метод рентгеновской дифракционной рефлексометрии (рентгеновский дифрактометр Brucker D8 Discover - ЦКП ИФМ РАН) использован для измерения толщины, шероховатости и плотности углеродных слоев.

Для определения оптических характеристик слоев использована спектроскопия комбинационного рассеяния света (возбуждение лазером с длиной волны $532 \mathrm{Hм}$ ).
Электрические свойства изучены с помощью измерений эффекта Холла (в геометрии Вандер Пау) при комнатной температуре (установка Nanometrics HL5500PC) и путем измерения слоевого сопротивления в диапазоне температур от 10 до $300 \mathrm{~K}$ (гелиевый криостат замкнутого цикла Janis-300).

Исследования образцов методом рентгеновской фотоэлектронной спектроскопии (РФЭС) проводились на комплексе Multiprobe RM (Omicron Nanotechnology $\mathrm{GmbH}$, Германия). Для получения спектров использовалось $\mathrm{Al} K_{\alpha}$-излучение. Диаметр области анализа составлял $\sim 3$ мм. Для определения соотношения концентраций углерода с $s p^{2}-$ и $s p^{3}$-гибридизацией производилась запись фотоэлектронной линии С $1 s$. Помимо этого, контролировались области, соответствующие $\mathrm{O} 1 s, \mathrm{Ga} 3 d$, As $3 d$, $\mathrm{Si} 2 p$ и $2 p$-линиям металлов, для определения однородности покрытия по толщине. При записи спектров анализатор энергии функционировал в режиме постоянной энергии пропускания (50 эВ) с абсолютным разрешением на уровне 0.3 эВ. Сопутствующее спектральное разрешение определялось на уровне 0.8-1 эВ; исходя из этого был выбран оптимальный шаг 0.2 эВ по оси энергий. Математическая обработка спектров проводилась с использованием программного обеспечения SDP v. 4.3. При спектральном разложении C $1 s$ на компоненты были использованы данные о сдвигах и коэффициентах асимметрии фотоэлектронной линии из $[9,10]$.

Состав и профили распределения элементов в GaAsструктурах с углеродными слоями исследованы методом вторичной ионной масс- спектрометрии (установка TOF SIMS 5 - ЦКП ИФМ РАН).

Структуры с КЯ и нанесенным поверх покровного GaAs слоя углеродным покрытием исследовались методами фотолюминесценции (при $77 \mathrm{~K}$ ) и электролюминесценции (при 77 и $300 \mathrm{~K}$ ). С помощью установки на базе монохроматора МДР-3 по схеме с синхронным детектированием и модуляцией сигнала измерены также спектры фототока при $300 \mathrm{~K}$. Следует отметить, что полученные методом ИЛН углеродные пленки обладали высокой механической прочностью и химической стойкостью. Поэтому для исследований электролюминесценции и сигнала фототока структуры были разделены на чипы размером $(2 \times 2)$ мм, и в процессе измерений использовался прижимной контакт к углеродному слою. Co стороны подложки $n^{+}$-GaAs омический контакт формировался искровым вжиганием оловянной фольги.

\section{3. Экспериментальные результаты и их обсуждение}

Спектры рентгеновской дифракционной рефлексометрии снимались в малоугловой области, и подгонка экспериментальных спектров к модели с помощью программного обеспечения установки позволяла определять параметры поверхностных слоев. По результатам метода скорость нанесения углеродных слоев составляла 
$0.19 \mathrm{Hм} / \mathrm{c}$ при температуре процесса $T_{g}=500^{\circ} \mathrm{C}$. Для этой температуры нанесения шероховатость увеличивается от 1.2 до 5.9 нм с ростом времени нанесения от $t_{g}=20$ до $120 \mathrm{c}$. Плотность материала $(d)$ также увеличивается от 2.00 до 3.09 г $/ \mathrm{cm}^{3}$ при вышеуказанных значениях $t_{g}$. При низких температурах нанесения (200 и $\left.300^{\circ} \mathrm{C}\right)$ и $t_{g}=120$ с шероховатость невысока $(1.7 \mathrm{Hм})$, $d \approx 2.85$ г $/ \mathrm{cm}^{3}$. При этом скорость роста уменьшается до $0.11 \mathrm{HM} / \mathrm{c}$.

Спектры комбинационного рассеяния света (КРС) показали наличие характерных для углеродных слоев пиков (рис. 1): узких пиков D при $1350 \mathrm{~cm}^{-1}$ и $\mathrm{G}$ при $1580 \mathrm{~cm}^{-1}$, а также широких пиков 2D малой интенсивности при $2690 \mathrm{~cm}^{-1}$ и $\mathrm{D}+\mathrm{D}^{\prime}\left(2940 \mathrm{~cm}^{-1}\right)$. Форма спектра соответствует в основном спектру КРС нанокристаллического графита [11] и сильно отличается от спектров аморфного углерода и алмазоподобных пленок углерода. Интенсивности пиков D и $\mathrm{G}$ снижаются при уменьшении температуры нанесения, и при $T_{g}=300$ и $200^{\circ} \mathrm{C}$ пики практически сливаются, а полоса $2 D$ исчезает. Отношение интенсивностей пиков $I_{D} / I_{G}$ зависит от условий нанесения пленок методом ИЛН: при невысоких $(<360$ c) временах нанесения это значение становится меньше единицы.

Анализ методом РФЭС углеродного слоя, нанесенного при $500^{\circ} \mathrm{C}$ в течение 105 с на поверхность $i-\operatorname{GaAs}(100)$, показал, что покрытие являлось сплошным, так как не был выявлен сигнал от подложки GaAs. Концентрация углерода в слое составляла $94 \pm 1$ ат\% с небольшим ( $6 \pm 1$ ат\%) содержанием кислорода. В ходе спектрального анализа фотоэлектронной линии С $1 s$ (рис. 2) было определено, что основная часть углерода находилась в элементном состоянии. При этом отношение концентраций $s p^{2}$ - и $s p^{3}$-гибридизированного углерода составляло 14. Помимо этого, в системе на следовом уровне было отмечено присутствие химических связей углерода с кислородом $\mathrm{O}=\mathrm{C}$ и $\mathrm{O}-\mathrm{C}=\mathrm{O}$. Суммарная концентрация такого углерода составляла $<4$ ат\%. Помимо этого, при разложении было выявлено присутствие характерного для фотоэлектронной линии С $1 s \pi-\pi^{*}$-плазмона.

Измерение электрических свойств С-слоев методом эффекта Холла (геометрия Ван дер Пау) и корректное определение типа проводимости затруднено, вероятно, из-за низких значений подвижности носителей. Удельное сопротивление составляло $\sim 1 \cdot 10^{-2} \mathrm{OM} \cdot \mathrm{cm}$. Зависимость поверхностного сопротивления слоев от температуры измерений $\left(T_{m}\right)$ носит полупроводниковый характер (монотонно увеличивается при снижении $T_{m}$ от 300 до $10 \mathrm{~K})$. Отмечается наличие двух участков изменения проводимости: низкотемпературного в диапазоне от 9 до $\sim 20 \mathrm{~K}$ и высокотемпературного - от 40 до $300 \mathrm{~K}$. На рис. 3 показана зависимость логарифма слоевого сопротивления от $1 / T$. Можно полагать, что на низкотемпературном участке проводимость имеет активационный характер. На высокотемпературном участке зависимость аппроксимируется степенной зависимостью: величина $\left(1 / R_{S}\right)$ пропорциональна приблизительно $T^{0.5}$.

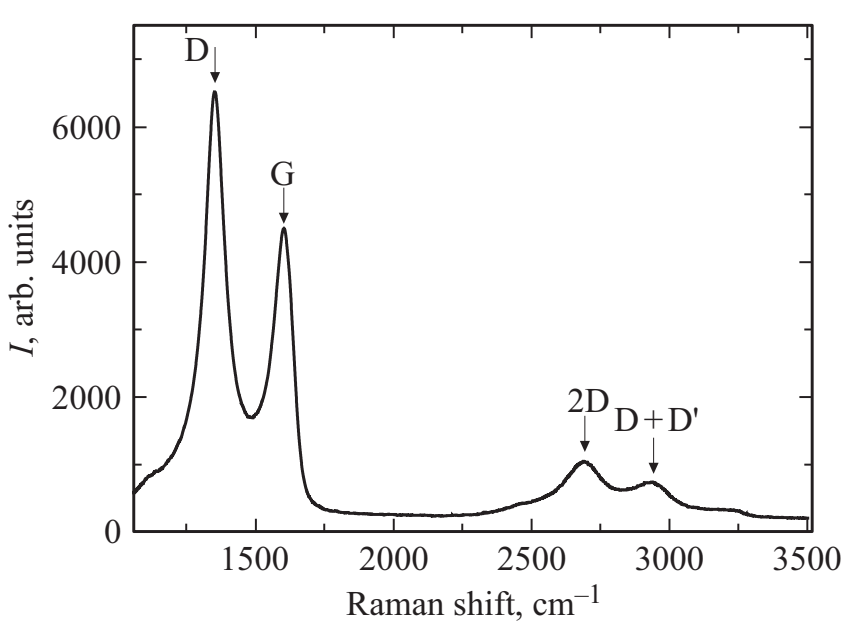

Рис. 1. Спектры комбинационного рассеяния света для углеродного слоя, нанесенного методом ИЛН при $500^{\circ} \mathrm{C}$ в течение 360 с на подложку $\mathrm{Si}(100)$.

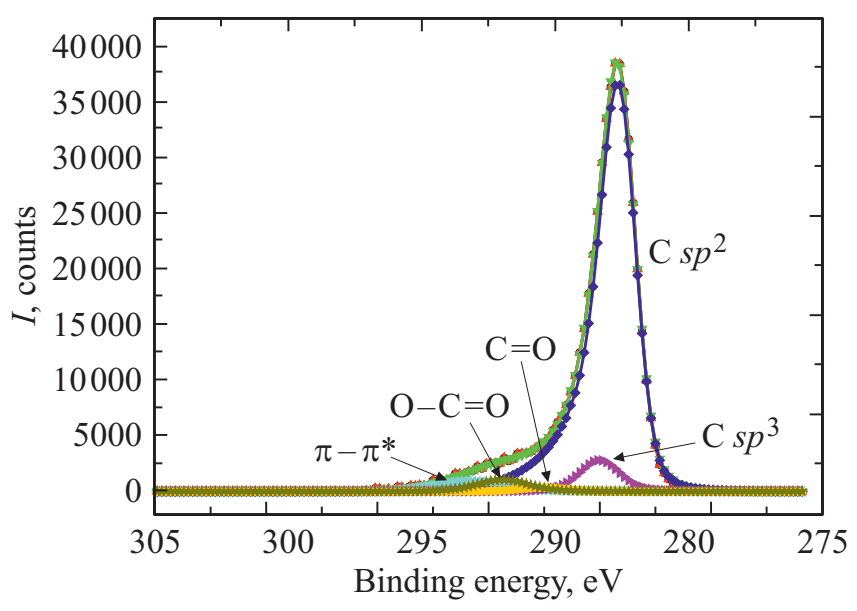

Рис. 2. Спектр фотоэлектронной линии С $1 s$, полученный методом РФЭС для углеродного слоя, нанесенного при $500^{\circ} \mathrm{C}$ в течение 105 с на подложку $i-\operatorname{GaAs}(100)$.

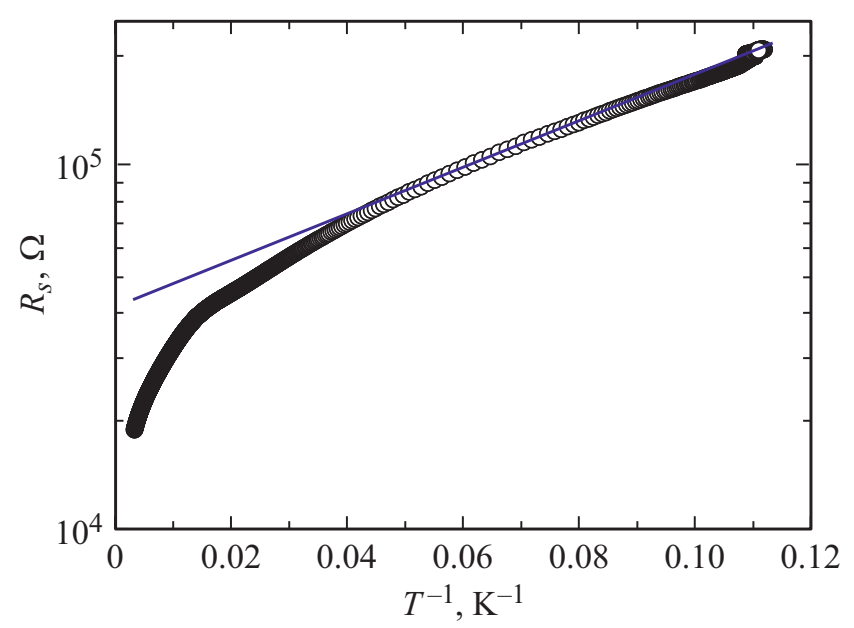

Рис. 3. Температурная зависимость слоевого сопротивления углеродной пленки, нанесенной на $i-\operatorname{GaAs}(100)$ при $500^{\circ} \mathrm{C}$ в течение 40 с. Прямая линия аппроксимирует низкотемпературный участок зависимости. 


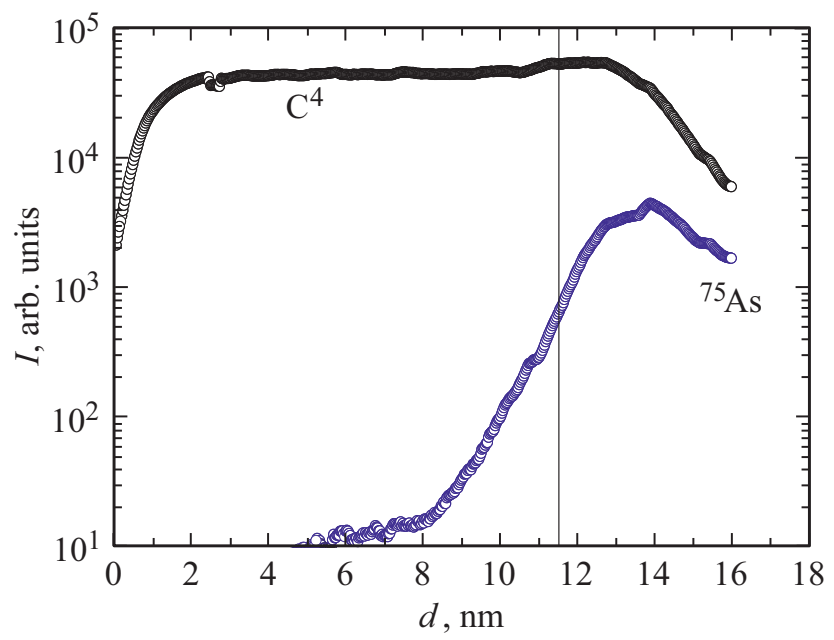

Рис. 4. ВИМС-профиль распределения атомов С и As в структуре с углеродным слоем, выращенным на подложке GaAs при $500^{\circ} \mathrm{C}$ в течение 60 c. Распыление осуществлялось ионами цезия с энергией 1 кэВ. Вертикальная линия показывает номинальную толщину углеродного слоя.

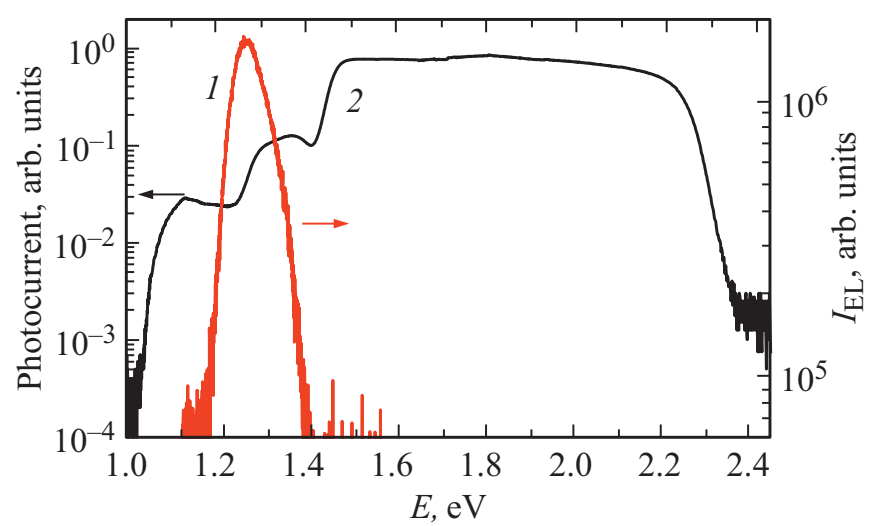

Рис. 5. Спектры электролюминесценции (1) и фототока (2) структуры с квантовой ямой InGaAs/GaAs и углеродным покрытием $\left(500^{\circ} \mathrm{C}, 4 \mathrm{HM}\right) . T_{m}=300 \mathrm{~K}, I_{\mathrm{EL}}=10 \mathrm{MA}$.

Профили элементов (рис. 4), полученные методом вторичной ионной масс-спектрометрии при использовании распыляющих ионов цезия с энергией 1 кэВ и анализирующих ионов висмута, были исследованы для структуры с углеродным слоем, выращенным на подложке GaAs при $500^{\circ} \mathrm{C}$ в течение 60 c. Профили показывают достаточно резкую границу раздела $\mathrm{C} / \mathrm{GaAs}$. Отмечается небольшое (до 2 нм) диффузионное проникновение атомов мышьяка из подложки в покрытие, а также „завал“ профиля углерода на поверхности (1 нм). Последнее, вероятно, связано с наличием на поверхности окисла, образующегося при хранении образца на воздухе. Наличие кислорода также выше зарегистрировано при исследовании методом РФЭС.

Измерение вольт-амперных характеристик структур с $\mathrm{C}$-слоями, изготовленными на подложках $\mathrm{GaAs}$ разного типа проводимости, показало, что выпрямление наблю- дается на GaAs $n$-типа. Это свидетельствует о том, что С-слои имеют $p$-тип проводимости, а на границе раздела $\mathrm{C} / \mathrm{GaAs}$ формируется потенциальный барьер.

Спектры фотолюминесценции структур с квантовой ямой (КЯ) InGaAs/GaAs c нанесенным углеродным слоем поверх покровного GaAs (20 нм) также соответствуют тому, что КЯ находится в поле барьера. Интенсивная электролюминесценция (ЭЛ) наблюдается (рис. 5) вплоть до $300 \mathrm{~K}$ даже при невысоких токах накачки (2-5мA). Пик ЭЛ расположен при энергии кванта 1.26 эВ $(300 \mathrm{~K})$. При измерениях ЭЛ прозрачный углеродный слой использовался в качестве токопроводящего покрытия.

Высокая фоточувствительность (фототок) для структур с КЯ и углеродным слоем наблюдалась при комнатной температуре в широком диапазоне энергий квантов (рис. 5, спектр 2) с „полочкой“ (максимальная чувствительность) при $1.5-2.2$ эВ. В отсутствие на поверхности углеродного слоя фоточувствительность практически не регистрируется.

Таким образом, углеродные нанослои, полученные методом импульсного лазерного нанесения, могут быть использованы для создания проводящих покрытий фоточувствительных и светоизлучающих GaAs-структур.

\section{Финансирование работы}

Работа выполнена при поддержке РФФИ (грант № 18-29-19137_мк). Отработка технологии лазерного нанесения осуществлялась при частичном финансировании Российским научным фондом (грант № 19-19-00545).

\section{Конфликт интересов}

Авторы заявляют, что у них нет конфликта интересов.

\section{Список литературы}

[1] Z.A. Ansari, T.J. Singh, S.M. Islam, S. Singh, P. Mahala, A. Khan, K.J. Singh. Optik, 182, 500 (2019).

[2] А.В. Елецкий, И.М. Искандарова, А.А. Книжник, Д.Н. Красиков. УФН, 181, 233 (2011).

[3] K.S. Novoselov, A.K. Geim, S.V. Morozov, D. Jiang, Y. Zhang, S.V. Dubonos, I.V. Grigorieva, A.A. Firsov. Science, 306, 666 (2004).

[4] A.V. Alaferdov, A. Gholamipour-Shirazi, M.A. Canesqui, Yu.A. Danilov, S.A. Moshkalev. Carbon, 69, 525 (2014).

[5] A.V. Alaferdov, R. Savu, T.A. Rackauskas, S. Rackauskas, M.A. Canesqui, D.S. de Lara, G.O. Setti, E. Joanni, G.M. de Trindade, U.B. Lima, A.S. de Souza, S.A. Moshkalev. Nanotechnology, 27, 375501 (2016).

[6] J. Hass, R. Feng, T. Li, X. Li, Z. Zong, W.A. de Heer, P.N. First, E.H. Conrad, C.A. Jeffrey, C. Berger. App. Phys. Lett., 89, 143106 (2006).

[7] Y. Bleu, F. Bourquard, T. Tite, A.-S. Loir, C. Maddi, C. Donnet, F. Garrelie. Frontiers Chem., 6, 572 (2018).

[8] H. He, X. Yu, Y. Wu, X. Mu, H. Zhu, S. Yuan, D. Yang. Nano Energy, 16, 91 (2015). 
[9] B. Lesiak, L. Kövér, J. Tóth, J. Zemek, P. Jiricek, A. Kromka, N. Rangam. Appl. Surf. Sci., 452, 223 (2018).

[10] A. Fujimoto, Y. Yamada, M. Koinuma, S. Sato. Anal. Chem., 88, 6110 (2016).

[11] A.C. Ferrari. Solid State Commun., 143, 47 (2007).

Редактор Г.А. Оганесян

\section{Carbon films obtained by a pulsed laser method and their influence on the properties of GaAs structures}

Yu.A. Danilov ${ }^{1,2}$, M.V. Ved'2, O.V. Vikhrova ${ }^{2}$, N.V. Dikareva ${ }^{2}$, M.N. Drozdov ${ }^{3}$, B.N. Zvonkov ${ }^{2}$, V.A. Kovalskiy ${ }^{4}$, R.N. Kriukov ${ }^{2}$, A.V. Kudrin ${ }^{1,2}$, V.P. Lesnikov' ${ }^{2}$, P.A. Yunin ${ }^{3}$, A.M. Andreev ${ }^{1}$

${ }^{1}$ Lobachevsky Nizhny Novgorod State University, 603950 Nizhny Novgorod, Russia

${ }^{2}$ Physico-Technical Research Institute of Lobachevsky Nizhny Novgorod State University, 603950 Nizhny Novgorod, Russia

${ }^{3}$ Institute for Physics of Microstructures, Russian Academy of Sciences, 603950 Nizhny Novgorod, Russia ${ }^{4}$ Institute of Microelectronics Technology and High-Purity Materials, Russian Academy of Sciences, 142432 Chernogolovka, Moscow Region, Russia

Abstract The properties of carbon layers obtained on GaAs substrates by pulsed laser sputtering of pyrographite in vacuum are investigated. The optimum temperature of the deposition process is $500^{\circ} \mathrm{C}$; the growth rate of the carbon layers was $0.19 \mathrm{~nm} / \mathrm{s}$. Raman spectra corresponded to the spectrum of nanocrystalline graphite. The carbon layers had $p$-type conductivity, demonstrated the semiconductor nature of the temperature dependence of the resistance, and were used as a conducting transparent coating of GaAs structures with an InGaAs quantum well. The structures exhibit significant electroluminescence even at low pump currents and photosensitivity in the range $1.5-2.2 \mathrm{eV}$ up to room temperature. 